\title{
Cultural Capital and the Sustainability of NGOs' Development Programs in Zimbabwe: An Integrative Approach
}

\author{
Phillip Mpofu ${ }^{1}$ \\ ${ }^{1}$ Department of African Languages and Culture, Midlands State University, Gweru, Zimbabwe \\ Correspondence: Phillip Mpofu, Department of African Languages and Culture, Midlands State University, \\ Gweru, Zimbabwe. Tel: 263-773-960-899. E-mail: phillip.mpofu@gmail.com
}

Received: June 11, 2012 Accepted: September 7, 2012 Online Published: September 27, 2012

doi:10.5539/jsd.v5n10p89

URL: http://dx.doi.org/10.5539/jsd.v5n10p89

\begin{abstract}
This paper examines the compatibility of the development programs which are implemented by the Non-Governmental Organizations' (NGOs) in the Midlands, Matabeleland and Masvingo provinces of Zimbabwe with the cultural sustainability and sustainable development in these cultural communities. This paper argues for the integration of cultural capital in the developmental projects which are implemented by the NGOs in the provinces of Zimbabwe. This paper is based on the data which was collected from five NGOs and six cultural communities which are the beneficiaries of the NGOs' development programs. The theoretical underpinnings of this paper are situated in cultural conservatism, a philosophy which valorises the traditional cultural institutions and the organic change of these cultural communities. This study establishes that, the programs implemented by the NGOs in Zimbabwe are predetermined and are detached from the cultures of the communities in which they are implemented. In view of the argument that culture is an important component in development, both as cultural capital and in defining development, this paper concludes that the prescriptive NGOs' development programs are detrimental to cultural sustainability and sustainable development in Zimbabwe. Therefore, this paper argues that there is need to integrate the cultural capital of the communities in the designing and implementation of the NGOs development programs in Zimbabwe.
\end{abstract}

Keywords: cultural capital, development programs, NGOs, cultural sustainability, sustainable development

\section{Introduction}

The impetus of this paper is on the bickering between the government of Zimbabwe and the Non-Governmental Organisations (NGOs) in the post-2000 period. According to Mpofu (2012), in this period the Zimbabwean scenario somewhat resembles serious antagonism between seemingly opposing but complimentary entities which are the government of Zimbabwe and the NGOs in Zimbabwe. This resentment resulted in the temporal closure of all NGOs in the year 2008 amid a hot-tempered political chapter, a development which comes after the deregistering of these organisations and the development of new regulations in the year 2007 which required the registration of all NGOs. Though this development was heavily criticised as an issue which was heavily castigated as unwarranted meddling with the civil society, this paper sets the politics marking foreign aid aside and looks at the compatibility of the NGOs' developmental programs with cultural sustainability and sustainable development in the Zimbabwean cultural communities. The major argument raised in this paper is the need for the integration of cultural capital in the developmental programs designed and implemented by the NGOs sector in Zimbabwe.

\section{Methodology}

In this section, the methodology is described in two stages- the first description is centred on how the data was gathered. The second part of the methodology presents the theoretical framework that shapes the analysis of the collected data.

\subsection{Data Gathering}

\subsubsection{Research Design}

In this study, a qualitative approach was followed since it is of specific relevance to the study of social relations (Flick, 2004). The qualitative approach enabled the researcher to interact with the sources of information in their natural setting. The plan of the study was carried out in form of a survey which entails a study of a limited 
number of NGOs and development programs with a view of drawing up conclusions that cover the generality of the entire group under review. Marshall and Rossman (2006) considers a survey as an appropriate mode of inquiry and making inferences about a large group based on data from a relatively small number of individuals in that group. The survey constituted a sample of five NGOs operating in six districts in Matabeleland, Masvingo and Midlands provinces of Zimbabwe. These are CARE International, World Vision International, Girl Child Network and Musasa Project and the Midlands Aids Service Organisation (MASO). The researcher selected different NGO's development projects with different agenda which included HIV/AIDS, human rights and children's rights and women rights, education and other developmental projects. This plan enhanced the chances of generalising the findings to the whole country on NGOs' activity by drawing inferences from a small portion of the population. Furthermore, the cost of conducting a survey was less than that of canvassing all the activities of all the NGOs in Zimbabwe. The researcher also gathered data from the beneficiaries of the developmental projects in Gweru, Zvishavane, Chivi, Zaka, Insiza and Hwange. Purposive and snow ball sampling methods were used in selecting NGOs, development projects and the facilitators of the programs. Stratified random sampling was used to select the beneficiaries of the development programs. The 'strata' being the six selected benefiting groups.

\subsubsection{Data Collection Techniques}

The collection of data for this research is characterised by the triangulation of four methods of which are the questionnaire method, interviews, observation, and document analysis. The first research instrument which was administered in the study is the questionnaire, which targeted the literate beneficiaries of the NGOs' development programs and the field officers working for these NGOs. The researcher adopted a wholly structured form where there are questions in three formats, namely, multiple choice formats, contingency questions and matrix questions (Flick, 2004). The questionnaires were sent by mail and e-mail to the selected organisations for distribution to their employees and the beneficiaries of their projects. They were collected in person by the researcher when he went to contact the interviews. Data was also collected through the use of structured and unstructured interviews, to cover the weaknesses of the questionnaire method. The interview method was selected for the reason that it is a free conversation which gives opportunity to participants to provide data without the limitations of space. The researcher visited the selected NGOs to conduct face-to-face interviews to enhance the benefits of the interview as a method of collecting data. Some interviews were done through telephone to those who were committed when the researcher visited the organisations. The researcher also conducted a thorough and systematic desktop research which is also known as document analysis. This strategically provided this study with the data and information that cannot be solicited through interviews and questionnaires. This involved exploring the literature on NGOs, foreign in Africa, culture and sustainable development as well as the organisation documents of the selected NGOs. This set a sound theoretical and practical base for making conclusions. Above all, the researcher observed the sustainability of NGOs' development programs and the neglect of cultural capital in the communities.

\subsection{Theoretical Underpinnings}

This study is informed by the cultural conservatism and cultural relativism theories. According to Brennan (1995), cultural conservatism is a philosophy which supports the preservation of the heritage of a nation or culture, or simply the traditions of the past. Allitt (1993) argues that cultural conservatism is a theory which is against foreign ideologies. The argument is that if change is envisaged in a community, it should be organic and not revolutionary. This is because the traditional institutions draws on the wisdom of many generations and have endured the test of time, while foreign ideologies may be masks for the preferences of other cultural groups. This study does not take a radical stance to the role of traditional institutions in sustainable development, but rather it adopts an integrative approach as evident in the liberal conservatism school which is a variant of conservatism which combines conservative values and policies with liberal stances. In essence cultural conservatives argue that that old institutions have adapted to a particular place or culture and therefore ought to be preserved. This argument valorises people's rights to their culture, to their own language and traditions.

This study is also informed by the theory of relativism which holds the view that the soundness, or even intelligibility, of any set of categories of thought is relative to its time, place or context of origin (Wiredu, 2004). This relativity is intended to exclude the possibility of critical evaluations of culture from the standpoint of other cultures in time, place or context. In this context, this thinking is against cross cultural evaluation of thought and universality in the NGOs' developmental projects. If cross-cultural evaluation is entertained in the agenda of the developmental projects implemented by NGOs in Zimbabwe, the African philosophy might become subordinated to Western philosophy since the western countries are the major sponsors of the NGOs in Zimbabwe. These theories are a demonstration that this paper subscribes to Sen (1999) who argues that cultural 
issues are critically important for development. There is link between culture and development such that, any development task would be unsuccessful if it does not have roots in a people's culture (Mbakogu, 2004).

\section{NGOs and the Developing World: A Theoretical Background}

This section discusses the intricacies and politics marking NGOs' activity in the developing countries as a background to the analysis of the NGOs development programs and their impact on cultural sustainability and sustainable development in Zimbabwe. The integration of cultural capital in the NGOs development programs requires an understanding of the politics of foreign aid. NGOs are defined as "private, self-governing, voluntary, non-profit distributing organizations operating, not for commercial purposes, but in public interest, for the promotion of social welfare and development, religion, charity, education and research" (Development Resource Centre: 1993, cited in Swilling and Russell, 2002). This account suggests that these organisations exist for simply good reasons. The NGOs are simply conduits for donations from independent donors which may be individuals, organisations or even countries. For instance, United States of America assistance reaches Africa through a variety of channels, which include USAID (Dagne, 2006).

At this juncture, it is important to note that the donors of NGOs in Zimbabwe are exclusively external and predominantly western. These organisations are not at all autonomous. In this light, Petras (1997) argues that NGOs are not necessarily non-governmental. This is because the NGOs are funded by foreign donors, a situation which obtains in Zimbabwe. This lack of independence is the source for the prescriptive agenda shaping their development programs. However, if the adage that 'he who pays the piper dictates the tune' is anything to go by, this point validates the interrogation of the invisible hand in the designing and implementation of NGOs programs and their effects to cultural sustainability and sustainable development.

This is not to say NGOs are a threat to the cultural communities of Zimbabwe. Rather, there is evidence that NGOs are increasingly considered important in bringing about other aspects of rural social change, serving as agents in the creation of civil societies and good governance, and otherwise fostering democratic and alternative approaches to mainstream development policy and practice (Riley, 2002). The problem is on the unilateral direction of foreign aid flows which makes the developed world the benchmark of development, such that the NGOs enter the Zimbabwean cultural communities with predetermined development approaches. This state of affairs demonstrates the fact that the NGOs development programs are not at all indigenous.

There are various arguments that have been raised in a wide range of scholarship on the problems and insincerity of foreign aid (Shivji, 2006; Boulding \& Hyde, 2004). In this body of literature, the over-arching argument is that that there is a unilateral flow of aid from the First world to the Third world countries, an implicit appreciation of the fact that the source of foreign aid are the developed countries. There is also recognition that the motivation for giving aid is not necessarily altruistic, rather over and above the humanitarian motives; aid is given for a variety of political, strategic, and economic reasons (Riddell, 1996). For instance, Israel is the largest cumulative recipient of US foreign assistance owing to the long standing strong bilateral relations between Israel and the United States of America and the shared strategic goals in the Middle East especially concerning Islamic extremism. These two countries also share the same democratic values; and historic ties dating back to US support for the creation of Israel in 1948. This nullifies the argument raised earlier on that aid is basically altruistic and meant for the developing nations.

Therefore, though, it can be envisaged that foreign aid is supposed to be beneficial to the cultural communities of Zimbabwe, the foregoing has shown that this can be contested. It has been exhibited in the foregoing that foreign aid is almost always political and aid giving is not necessarily altruistic. A close look at foreign aid indicates that the self-interest of the donor rather than philanthropic motivation more often than not motivates such programs since the NGOs come to Zimbabwe with predetermined programs. Conditionalities are the conditions which are set by the donor countries or organisations which are supposed to be met by the aid recipients if they are to constantly access aid. To buttress this view, Boulding and Hyde (2004) claim that rarely is foreign aid given without strings attached. These conditionalities as they have been applied to Zimbabwe include democracy and good governance; as well as aligning the NGOs agenda with the interests of the donor(s).

However, just like the predetermined agenda, these conditionalities deprive the recipient countries of their autonomy and fundamental rights to exercise self-determination in making decisions, thus cultural capital. Therefore, this carrot and stick method which is shown by the existence of conditionalities can compromise the cultural freedoms of Zimbabwe. As a result, the Zimbabwean people are becoming cultural clones of the aid givers through adopting the Western crafted development paradigms as shown by the NGOs' development programs. This is because the development discourse in the NGOs in Zimbabwe is dogmatic and inclined to Western forms of development as demonstrated by their development programs. 


\section{Cultural Capital and Sustainable Development}

This section is discusses the intricate relationship between culture and sustainable development, a subject which has been well covered in a wide scholarship. Oyeneye and Shoremi (1985) argue that culture is marked by its collectiveness in that it is shared by the members of a society; it is historically derived and transmitted from one generation to another; and it is created through the process of adjustment to the social setting. In this account, it can be concluded that the culture of a people is shaped by the environment and context. This pronouncement indicates that what makes particular cultural community exist may not apply in another cultural community. This is cultural relativism. This valorises the importance of culture as a resource and a tool for adaptability of the people to their particular situations. This is the basis for questioning the NGOs' development programs.

On the other hand, the term development is a multi-dimensional state and process involving a national condition of life from unsatisfactory to satisfactory. Sen (1999) argues that there is a link between culture and development and the connection relate both to the ends and to the means of development. This declaration means that there are two convoluted aspects connecting culture and development, which are the meaning/definition of development and how the process of development is realised (that is the resources/cultural capital and strategy for development). These are matters which can only be determined agreeably within the context of a single culture. Drawing an all-inclusive definition of development and the supposed development strategies might be deceptive. In summary, culture shapes what we mean by development and determines how that development can be realized. That is, man is the means and the end of development (Mbakogu, 2004). For that reason it must be emphasized that man's development is enhanced when he is socially and culturally fulfilled. Hence, development divorced from its human or cultural context is growth without soul (World Commission on Culture and Development, 1995).

As an illustration, Petras (1997) and Sen (1999) trace the astonishing economic success of Japan which has transformed from a formally backward economy into one of the most prosperous nations in the world. According to these scholars, Japan's success is attributed to the core elements of the Japanese culture which are based on Confucianism. Furthermore, Japan as a nation managed to shut out the western world as part of its ethos. According to Sen, it can be argued that the Japanese values have changed only a little, but the same ethical values as they were in the old tradition have not been substantially altered in a fast changing world. Because. This is testimony to the role of cultural capital is sustainable development.

In the recent years, development discourse has assumed a paradigm shift, the move that focuses on the ability of development strategies to provide for the needs of the world's current population without damaging the ability of future generations to provide for themselves. Thus today's decisions are made with considerations of sustaining the same activities and benefits in the long term future. This is basically doing something with the long term in mind. This is what is called sustainable development. The United Nations Report (1987) entitled Our Common Future defines sustainable development as "development that meets the needs of the present without compromising the ability of future generations to meet their own needs". The core philosophy of this development thought is to resolve the dilemmas of the past destructive development methods which failed to put into account the long term aims of social equity and environmental balance.

The arguments in this article buttress the issue of culture as a key topic in discussions of development and also sustainability of that development in Zimbabwe. Approaches to development that take into account matters of culture have the potential to transform communities and individuals in positive and meaningful ways over the long term unlike what is witnessed in the NGOs development programs. Entirely imported forms of development approaches which are merely aspects from other cultures do undermine other cultures and are not sustainable in the long term. This can be attributed to the incompatibility of the development programs implemented by the NGOs with the physical, social, political and cultural climate in Zimbabwe. Thus culture is an important pillar in sustainable development. This paper argues that culture in simple terms is not a pillar of sustainable development but the ability of the cultural communities in Zimbabwe to maintain the same cultural elements which forms the cultural capital from one generation to the next, thus cultural sustainability. Cultural sustainability means that change occurs in a way that respects cultural values and cultural capital of a people.

Cultural capital is essential for sustainable development in cultural communities since there are firm relationships which exist between culture and the development. From a policy viewpoint, as an illustration the government of Canada, the Agenda 21 for Culture and the UNESCO's Decade for Education for Sustainable Development (2005-2014) takes cultural development as connected to social policy and goals such as promotion of social inclusion, cultural diversity, rural diversity, rural revitalization, public housing, health, ecological preservation, and sustainable development. This shows how important cultural sustainability is in sustainable 
development to the effect that it warrants attention in policy making. Development that takes into account cultural sustainability promotes sustainable communities and this respects the history and character of those existing features that nurture a sense of attachment to, and familiarity with a place and its environment. It can be noted that the argument for cultural sustainability in NGOs' operations resonates the same sentiments of the struggle against cultural imperialism which characterizes the postcolonial African societies.

The NGOs, therefore should understand that African culture has got an absolute difference from that of the West in varying formalistic and thematic expressions; in fact there are simply divergent ideological formations which need to be appreciated. Ultimately, the agenda and conditionalities of the NGOs should take into account the cultures of the recipient communities. This can be enhanced by the minimisation or avoidance of predetermined development programs and improving the community participation in the crafting and implementation of these programs.

The research findings show that there is lack of a stern policy in Zimbabwe on the monitoring of NGOs to make sure that they work within the confinements of the cultural frameworks of the communities in the country. The NGOs' accountability is directed upwards to the donors and instead of the communities. This is vital for the implementation of democratic and participatory development. Hence, development and sustainable development are elaborate phenomena which are culturally, situational, and institutionally entrenched such that they can be delicate if universalistic, 'one solution fits all' paradigms are promoted.

The thesis of this paper therefore is premised on the need to appreciate cultural diversity and the reliance on the tried and tested traditional institutions which are cultural capital needed for sustainable development. In line with this thought, NGOs in Zimbabwe should have broad comparative knowledge of their target cultural communities. The participants' views reflect that the NGOs' needs analysis results are not always congruent to the needs of the people in those communities. As a result, there is divergence between the implemented programs and the cultural capital of communities, in form and implementation.

\section{Findings and Discussion: The Dearth of Culture in NGOs Development Programs}

\subsection{Culture, Women/Children Rights and Gender in Zimbabwe}

The findings from the fieldwork carried out in the selected districts reveal that one of the key result areas marking the developmental programs of the NGOs in Zimbabwe entails advocacy and lobby issues. The Musasa Project, World Vision International and Girl Child Network are testimony to this admission. It was noted that in organisation of this mould, the advocacy and lobby departments have become mouth pieces of the girl child, women, and the communities as they lobby for policy and law reform in Zimbabwe. It was realised that what these organisations argue for are issues which not endogenous, but foreign to the cultures in Zimbabwe. Rather it is a case of sponsored activism since the driving force behind the employees of these organisations who are the 'activists' are the funds from donors and not the motivation to help the communities. It was noted that the advocacy and lobby programs are the most difficult to implement in Zimbabwe due to the lack of consideration cultural capital in the designing and implementation of the programs.

The intention of advocacy and lobby program is policy and law reform. In this regard, the Musasa Project boasts on its website for contributing to the enactment of the Domestic Violence Act of 2006 as a milestone to the organisation's activities. They regard it as a significant step forward for the organisation. They also stress on the contentious but dormant Legal Age of Majority Act of 1982 regardless of its continued existence with nominal application for a substantial period. It was exposed during the fieldwork that Domestic Violence Act as a statutory instrument undermines the culture of the Zimbabwean cultural communities in a number of respects. It is offensive to notice that the marital and sexually related issues which have always been private matters have been pushed into the public sphere because of such ominous laws. Aptly speaking, the Act gives women rights which are culturally unacceptable which does not absolutely build sustainable homes. Furthermore, the role of the traditional leadership in dealing with 'domestic' crimes has been diminished since such issues are now presided in courts of law or incongruous personnel at organisations in the mould of Musasa Project.

This exposed points to the ensuing clash of the law and culture. In this vein, Cotterrell (2004) sceptically interrogates the relationship between law and culture. What is encompassed by the idea of culture is actually the content of different types of social relations and the networks in which they exist. Therefore, the conflict that exists between law and culture emanates from the notion that culture has its own values and laws to express certain values from which they originate. The consequence is that legal theory must systematically take account of the notion of culture. In this regard, Cotterrell (2004) argues that "legal theory requires a sociologically-informed concept of community". However, the laws that are being advocated for by these NGOs 
in Zimbabwe, through their development programs do not consider the cultural values obtaining in the Zimbabwean cultural communities.

Though the Musasa Project is professed to be a Zimbabwean organization founded in 1988 to reform institutions that perpetuate violence against women through developing strategies that assist in combating subordination of women, its agenda and funding is not at all Zimbabwean. The organisation has adopted an increasingly radical feminist agenda for cultural change in Zimbabwe, disregarding the role of cultural capital in development. Its programs are challenging existing values and represent an alternative view in Zimbabwe. The participants noted that, though as part of its agenda, the organization have got seemingly good issues as part of its agenda, the major problem is that the problems identified are products of judgements based on Western culture and even the solutions provided to the problems are not rooted in the cultures of Zimbabwe.

\subsection{Cultural Extension through NGOs Programs}

The participants' contributions reveal that the NGOs in Zimbabwe, through their development programs are active agents of cultural extension in the political, economic, social and spiritual aspects of human life. Though there are some NGOs which are offering empathetic assistance to the cultural communities in Zimbabwe for example in the areas of food aid, education, and HIV/AIDS, some NGOs' developmental programs are premised on verdicts by donor countries on the Zimbabwean cultural communities aimed at dislodging the indigenous cultures. For example, feminism is a foreign construct which is professed to promote gender equality, disregarding the complimentary gender roles in Zimbabwean cultural communities. Therefore, the NGOs in Zimbabwe should integrate the aspect of cultural capital in their development programs.

The other organisation in the mould of Musasa Project in Zimbabwe is the Girl Child Network (GCN) which is aimed at protecting and promoting the rights of the girl child and to support the economic, political, social and cultural empowerment of the girl child in order for her to assert those rights in the home, school and community. The organisation also advocates for laws and policies that minimise what it considers gender based violence, something which is to some extent similar to Musasa Project's agenda. It also campaign and lobby for total elimination of what it perceives to be harmful cultural practices that impede the full development of the girl child. The claim of the existence of harmful cultural practices in the Zimbabwean cultural communities is absolutely judgemental and rejection of cultural plurality. It can be envisaged in the foregoing that the initiative is to change cultural beliefs and substituting them with western culture. This jeopardizes cultural sustainability and sustainable social development in Zimbabwe.

Furthermore, some NGOs are aimed at expanding the Christian religion. The Zimbabweans cultural communities are considered to have no form of spirituality or inferior religion such that Christianity has triumphed over local customs and indigenous knowledge in Zimbabwe. Against this background, NGOs such as World Vision International, Christian Care and other "faith based" organisations appear to be appendages of the early missionaries in Zimbabwe in the spreading of the Christian faith, by instilling Christian values through whatever means possible. For example the program Channels of Hope implemented by World Vision International in Matabeleland in 2009 which was aimed at training of pastors, an exercise dubbed the 'training of trainers' aimed to educate opinion leaders. This concerns the targeting of the opinion leaders who can influence the ordinary people in their respective areas. This is a reflection of the rejection of the role of spirituality in sustainable development. In this regard, Mbiti (1969) argues that traditional African religions permeate all developments of life such that, there is no strict division between the sacred and the worldly or between the religious and the non religious, between the spiritual and the material areas of life. Wherever the African is, there is his religion. For that reason, "it is doubtful that Christianity could provide a blueprint for organising African societies: those teachings are irrelevant because they do not speak meaningfully to the religious, social, political and philosophical foundations on which the social institutions in Africa are constructed (p'Bitek, 1986).

The other form of cultural extension is witnessed in the child sponsorship programmes by SOS Children's Home and World Vision International which are merely cultural extensions in the raising of the African child. For example, the SOS Children's Home has the aid programmes which tend to focus on one child in a family who is said to be vulnerable, or a family among families. Similarly, World Vision has got child sponsorship programs where the field officers help the sponsors in the identification of the children they can sponsor while they are in their Western home countries by sending photographs to the United States. The selected child is then sponsored in almost everything by the "foreign parent". The sponsor who is also now a 'parent' communicates with the "new child". The nature of the interaction between the sponsor and the child reveals that Child sponsorship programme is a new-fangled form of child adoption since the sponsor can visit the child. The role of the real parent is displaced, which might be the source of problems in the real family in the future. As a result the feeling 
of the child ends up being that he/she has since found a new and more responsible parent. More so, the approaches of World vision and SOS in child caring, cultivates the spirit of individualism. However, as far as Africans are concerned, the reality of the communal world takes precedence over the reality of individual life circumstances (Adewole, 1990). This shows that there is close link between the society and the individual to the rest of the society, in simple terms no person is a free agent. This is supported by Wiredu (2004) who says that African ethics would be of a communalistic kind, the interests of the individual are placed in a reciprocal adjustment with the interests of the community with reference to many specific circumstances of life. Therefore, the cultural shift which has been exposed here is the shift from the communalistic to individualistic systems of the perceptions and relations in the communities, a shift which is alien to the Zimbabwean cultural communities.

The other issue which is topical, in the day-to-day business of Musasa Project and Girl Child Network which connects with the discussion in the previous paragraph is the issue of human rights. Musasa Project gives emphasis on the women rights, while Girl Child Network focuses on children rights which inadvertently are women rights since the focus is on the girl child. Nevertheless, the formulation of human rights standards and their enforcement mechanism and procedures are fraught with controversy. What is meant by human rights is the set of normative standards enshrined in the International Bill of Rights, as composed of the Universal Declaration of Human Rights, the International Convention of Civil and Political Rights, and the International Covenant on Economic, Social and Cultural Rights, and other human rights instruments. However, like in most of the international formulations, the Western nations play a leading role in their promulgation, but they have a universal value in the application. In this light, it is evident in the Zimbabwean cultural communities that the issue of individual rights, women or children has caused the disintegration of families, yet the family is a key institution in the African societies and the starting point in human development.

\subsection{The Destruction of Social Institutions}

The participants' views demonstrate that the NGOs' development programs contribute to the destruction of the social institutions which sustains the Zimbabwean cultural communities. It was established that the selection and recruitment process of the NGOs' employees in Zimbabwe gives careful consideration to the educational qualifications of the applicants. The majority of field officers who facilitate the development programs of the NGOs are in possession of at least a diploma or a degree in the disciplines of education or other humanities. More so, they are also predominantly young and unmarried. However, though they lack wisdom from experience by the standards of the Zimbabwean cultural communities, they are engaged in various programs in their respective organisations which include counselling, teaching, instructing, training, and performing other leadership roles depending on the programmes they facilitate. Some of the programs include sex education which might include activities like condom use demonstrations in the case of World Vision International, Musasa Project, and MASO as well as marriage counselling at Musasa Project. This is testimony to the point that, the role of the African child is changing because he is now a counsellor just because he has got academic qualifications, yet they were supposed to be taught themselves by the elderly who have the practical knowledge acquired through experience.

This is a reflection of the inappropriateness of the programs implemented by some of the NGOs in Zimbabwe. The development programs of NGOs reflect the inappropriateness of the mentor to the subject, situation, and the audience. This is in sharp contrast of the setting of the traditional Zimbabwean communities which had proactive and organised systems of education with regards to the socialisation of the child. Sex education was part of the knowledge which was acquired by young people proactively and not reactionary in preparation of adulthood and its demands such as marriage. The instruction was continuous unlike what is now done by the NGOs where it is taught at prearranged workshops to react to the problems affecting the societies. The crafting of similar programmes in the contemporary society can be done taking a cue from the traditional culture. The demise of the social morality of the indigenous culture can be attributed to the alienation of the indigenous people from their culture through some NGOs development programs which disregards the cultural capital of the cultural communities of Zimbabwe. Though it is noble for NGOs to assist in solving problems bedevilling the communities, it is worth noting that there is a marked degree of ignorance of the elements in the core (traditional) culture which can direct the present generation in the implementation of the same kind of the education. Therefore, there is need for the integration of cultural capital in the development programs for the sustainability of the NGOs' programs.

According to p'Bitek (1986), "men live in organisations called institutions: the family and the clan, chiefdom and kingdom or an age set system. They have a religion, any army, legal and other institutions." All these institutions are informed by, in fact built around the central ideas about what life is all about that is rooted in their social philosophy, and their world view. In this vein, Chiwome (2000) argues that marriage is a primary 
value since Shona society is organised around the family; it is the foundation of the clan. This shows how important and integral the family institution is to the functioning of the Shona society. In view of this exposé, the Musasa Project is failing to protect the core institution of the Zimbabwean cultural communities. This is because the organisation disregards the local cultural capital as it considers divorce as an alternative where there is a conflict in the marriage institution, which is in sharp contrast to the values of the communities in Zimbabwe.

The activities of the Musasa Project seem to be ignorant of the fact that the family is a very important pillar in the lives of the Zimbabwean people. In the event of a conflict, the woman who is said to be a canonical victim is given shelter, such that when the husband comes he is now a stranger to the family, yet he is the head of that family. The aspect of sustainable progression in the family and society at large is destroyed. In respect of the position of the marriage institution, Matambirofa (2006) notes that it is general expectation of members of the Zimbabwean society that no matter how 'professional' a woman may become, they must still marry and in the institution of marriage, the woman is expected to subordinate herself to her husband. The shallow thinking of viewing women as always at the receiving end in marriage shows the failure to recognise the fact that Zimbabwean woman have throughout history, shared political power with man.

\subsection{NGOs, the Environment and Culture in Zimbabwe}

The participants from the various districts concurred on the view that the NGOs' developmental programs are implemented without consideration of the climate and environment of the local communities. Culture is a product of the people's endeavour to adapt with the environment. Zimbabwe is a country with varying climatic conditions depending with location. This is shown by the existence of five farming regions which have been identified, which suggests that the farming projects and methods, as well as the livestock of these five regions are expected to be different. Though, the climatic conditions in Zimbabwe range from favourable to unfavourable, it has been proven that every farming region is productive in its own way. Thus climate plays an enormous role in the formation of a civilisation, which is culture. However, some of the NGOs implementing farming related projects in Zimbabwe tend to ignore the varied climatic regions in Zimbabwe in their 'one size fits all' approach to development.

World Vision International and CARE International irrigation schemes and input programmes respectively provide good examples to this problem. The Malole irrigation scheme of 2008 in Matabeleland epitomises this problem. The problem of water in Matabeleland is a well not fact such that any project which requires a lot of water like irrigation is not sustainable, just like what happened to this project by World Vision International which is now part history. More so, the nutrient gardens which were supposed to be put in place by this Malole project had exotic crops and trees which did not provide immediate needs for that particular community. In the agriculture sector in Zimbabwe, Matabeleland is well known for cattle ranching and small livestock farming. In this regards, the World Vision International Heifer Scheme of 2007 was in the right direction, but the problem was on the breed of the cattle which struggled to survive in the climatic conditions obtaining in this region.

The projects in some part of Masvingo province and Gweru urban have also raised questions on their applicability to supposed beneficiaries. The agricultural input distribution schemes have been implemented in Masvingo without considering that this farming region is suitable for drought resistant crops such as sorghum, millet and rapoko. As a result the projects did not contribute meaningfully to the development of the cultural communities in places such as Zaka and Chivi. The case of Gweru urban where Care International is implementing numerous gardening projects is an indication that needs analysis was not properly carried out. If the people of Mkoba, Senga or Mtapa high density suburbs in Gweru where involved in the construction of programs, the participants revealed that not a soul was going to suggest the program of gardening considering the numerous competing demands in urban centres which include housing, employment, revamping of industries and urban infrastructural development. More so, it is argued that urban agriculture is responsible for degradation of land and water resources and exploiting land which is supposed to be used for urban development (Bryd, 2002). Against this background it was recognized that the NGOs do not consider such issues out of ignorance and negligence as well as arrogance. Ultimately, the regions such as Zaka and Chivi experience perennial droughts because they concentrate on crops which are not commensurate to the climate of the region. This failure by the NGOs to recognise the influence of philosophy and physical climate in shaping culture has made them to craft and implement development programs which are inappropriate and therefore not sustainable.

\section{Recommendations: Integrating Cultural Capital in NGOs' Development Programs}

It has been exhibited in this paper that the NGOs' development programs are detrimental to the cultural institutions and philosophy of the cultural communities in Zimbabwe. They do not take into consideration of the role cultural capital in cultural sustainability and sustainable development. This paper argues for the integration 
of cultural capital enshrined in the human factor which is important for the sustainability of development into the NGOs' programs. In order to achieve cultural sustainability, responses from the fieldwork show that the NGOs' programs should be reviewed before the aid programs could be implemented, with the cultures of the local communities as the benchmark. This can be the starting point in making the giving of the donor agencies selfless response mechanism that should be driven by public needs. This can be done if donor agencies would seek to appreciate the culture of the communities in which they operate, before implementing programs. This can help subvert the universal approaches to development which fail to appreciate diversity and in the process deprive the recipient communities of their cultural capital. Donor agencies should not substitute, but rather support the economic, political, agricultural and socio-cultural systems of the communities. This can be achieved if thorough and faithful consultations on the needs of the communities could be done culture and development experts who in turn informs the NGOs on the crafting of the development programs. Furthermore, the government should also craft stern policy and regulation to regulate NGOs' activity aimed at defending the cultural capital of communities in Zimbabwe.

\section{Conclusion}

This paper has argued that the NGOs' development programs implemented in Zimbabwe are predestined for the reason that they are developed without the considerations of the cultures of the communities in Zimbabwe. As a result, the NGOs promote universal development approaches which disregard cultural capital and therefore are inimical to cultural sustainability and sustainable development. In view of the importance of culture in development, both as a resource and as a determinant of development, this paper argues that the maintenance of the cultural capital, which is cultural sustainability, is crucial for development which is sustainable. Therefore, it is imperative for the NGOs in Zimbabwe to integrate the cultural capital of the recipient communities in the designing and implementation of development programs.

\section{References}

Adewole, A. (1990). African Philosophy. In Ikenga-Metuh, E., \& Ojoade, O. (Eds.). Nigerian Cultural Heritage. South Onitsha: Imoco Publishing Company.

Allitt, P. (2004). Catholic Intellectual and Conservative Politics in America. New York: Cornel University Press.

Boulding, C., \& Hyde, S. D. (2004). Democratisation and Foreign Aid: When do Donors Withdraw Aid and Why? Paper Presented at the Western Political Science Association. Retrieved from http://aix1.uottawa.ca/ brown/pages/Stephen_Brown_EJDR.pdf

Brennan, M. C. (1995). The Conservative Capture. Chapel: University of North Carolina Press.

Bryd, E. (2002). Agriculture and Human Values, Potentials, Problems and Policy Implications for Urban Agriculture in Developing Countries, Vol. 26, Nepal: UNDP.

Chiwome, E. M. (2000). Introduction. In Chiwome, E. M. et al. (Eds.). Indigenous Knowledge and Technology in African and Diasporan Communities: Multidisciplinary Approaches. Harare: Mond Books.

Cotterrell, R. (2004). Law in Culture. Ratio Juris, 17(1), 1-14. March 2004. http://dx.doi.org/10.1111/j.0952-1917.2004.00251.x

Dagne, T. (2007). Africa: US, Foreign Assistance Issues, CRS Report for Congress. Retrieved from http://fpc.state.gov/documents/organization/71787.pdf

Flick, U. (2004). An Introduction to Qualitative Research. New Delhi: Sage.

Marshall, C., \& Rossman, B. G. (2006). Designing Qualitative Research. New Delhi: Sage.

Matambirofa, F. (2006). The Problematics of a Feminist Ontology: Reflections on the Women Writers Poetry Project- Ngatisimuke: Nhapitapi Yenhorimbo. In Mguni, Z., Furusa, M., \& Magosvongwe, R. (Eds.). African Womanhood in Zimbabwean Literature: New Critical Perspectives on Woman's Literature in African languages. Harare: College Press.

Mbakogu, I. A. (2004). Is There Really a Relationship Between Culture and Development? Retrieved from http://www.krepublishers.com/../Anth-06-1-037-043-2004-Mbakog

Mbiti, J. (1969). African Religions and Philosophy. London: Heinemann.

Mpofu, P. (2012). The Dearth of Culture in Sustainable Development: The Impact of NGOs' Agenda and Conditionalities on Cultural Sustainability in Zimbabwe. Journal of Sustainable Development in Africa, 14(4), 191-205. 
Oyeneye, O., \& Shoremi, M. (1985). The concept of culture and Nigerian society. In Oyeneye, O., \& Shoremi, M. (Eds.), Nigerian life and culture: A Book of Readings (pp. 1-13). Ago-Iwoyi: Ogun State University.

P'Bitek, O. (1986). Artist the Ruler: Essays on Art, Culture and Values. Nairobi: Heinemann.

Petras, J. (1997). Imperialism and NGOs in Latin America, Monthly Review, 49(7). Retrieved from http://hmb.utoronto.ca/HMB303H/.../Petras_LatAmericaNGOs.pdf

Riddell, R. (1996). Aid in the 21st Century. UNDP.

Riley, J. M. (2002). Stakeholders in Rural Development. California and London: Sage.

Sen, A. (1999). Development as Freedom. New York: Knopf.

Shivji, I. (2006). The Silences in the NGO Discourse: The Role and Future of NGOs in African Development, $X X X I(4), 22-51$. Council for the Development of Social Sciences Research in Africa.

Swilling, M., \& Russell, B. (2002). The Size and Scope of the Non-profit Sector in South Africa. Durban: Centre for Civil Society, University of Natal.

WCED. (1987). Our Common Future. Oxford: Oxford University Press.

Wiredu, K. (2004). A Companion to African Philosophy. Malden and Oxford: Blackwell Publishers. 